FEDERAL RESERVE BANK OF SAN FRANCISCO

WORKING PAPER SERIES

\title{
Why Is Current Unemployment So Low?
}

\author{
Andreas Hornstein \\ Federal Reserve Bank of Richmond \\ Marianna Kudlyak \\ Federal Reserve Bank of San Francisco
}

February 2020

Working Paper 2020-05

https://www.frbsf.org/economic-research/publications/working-papers/2020/05/

\section{Suggested citation:}

Hornstein, Andreas, Marianna Kudlyak. 2020. "Why Is Current Unemployment So Low?”

Federal Reserve Bank of San Francisco Working Paper 2020-05.

The views in this paper are solely the responsibility of the authors and should not be interpreted as reflecting the views of the Federal Reserve Bank of San Francisco or the Board of Governors of the Federal Reserve System. 


\title{
Why Is Current Unemployment So Low? *
}

\author{
Andreas Hornstein ${ }^{\dagger} \quad$ Marianna Kudlyak ${ }^{\ddagger}$
}

February 19, 2020

\begin{abstract}
Current unemployment, as of 2019Q4, is so low not because of unusually high job finding rates out of unemployment, but because of unusually low entry rates into unemployment. The unusually low entry rates, both from employment and from out of the labor force, reflect a long-run downward trend, and have lowered the unemployment rate trend over the recent decade. In fact, the difference between the current unemployment rate and unemployment rates at the two previous cyclical peaks in 2000 and 2007 is more than fully accounted for by the decline in its trend. This suggests that the current low unemployment rate does not indicate a labor market that is tighter than in 2000 or 2007.
\end{abstract}

Keywords: Unemployment. Job finding rate. Job separation rate. JEL No. E24, E32, J11, J63, J64.

${ }^{*}$ The authors thank Dan Wilson and Rob Valletta for very helpful comments. We thank Mitchell Ochse for excellent research assistance. Any opinions expressed here are those of the authors and do not reflect the opinions of the Federal Reserve Bank of San Francisco, the Federal Reserve Bank of Richmond or the Federal Reserve System.

${ }^{\dagger}$ Federal Reserve Bank of Richmond, andreas.hornstein@rich.frb.org

${ }^{\ddagger}$ Federal Reserve Bank of San Francisco, marianna.kudlyak@sf.frb.org 
Unemployment has fallen steadily over the past decade and is now at a fifty-year low, suggesting a tight labor market. Yet, despite this exceptionally low unemployment rate, wage growth remains moderate. We reconcile the two observations by arguing that the current low unemployment rate reflects a secular decline in the trend unemployment rate, and that the current gap between actual and trend unemployment remains within historical bounds.

Unemployment can be low because the rate at which people exit unemployment is high or because the rate at which people enter unemployment is low. We find that, in contrast to previous business cycle peaks when unemployment was low because of the high rates at which people exited unemployment (high job finding rates), current unemployment is low because of the low rates at which people enter unemployment. Specifically, we attribute the entire decline in the unemployment rate trend over the last decade to the long-run decline in the entry rates to unemployment from employment and from out of the labor force. In addition, the role of the job finding rate in driving the decline in the cyclical component of the unemployment rate since 2015 is smaller as compared to its role at previous business cycle peaks.

The unemployment rate at a point in time is well-approximated by a function of the rates at which people flow (transition) between the three basic labor market states: unemployment, employment, and out of the labor force (OLF). We construct these flow rates using Current Population Survey (CPS) micro data and use them to calculate contributions of the flow rates to movements in the unemployment rate since the mid-1970s.

During expansions, the unemployment inflow rate from employment typically declines and the unemployment outflow rate to employment (job finding rate) increases. The current recovery is characterized by an out-sized decline in the inflow rate into unemployment, and somewhat limited improvement in the outflow rate to employment, which has remained below its pre-recession peak. Counterfactual exercises confirm that the largest contribution to the current low unemployment rate comes from the low unemployment inflow rate from employment, and the second largest contribution comes from the low unemployment inflow rate from OLF.

We construct a trend of the unemployment rate from the trends of the flow rates. First, we find that the unemployment rate trend has fallen substantially during the last decade. This decline in the trend accounts for the entire difference between the unemployment rate during the previous business cycle peaks of 2000 and 2007 and current unemployment. Second, the entire decline in the unemployment rate trend can be accounted for by the long-run declines in the inflow rates to unemployment. Third, in 2019Q4, the estimated unemployment trend is at 4.4 percent. Comparison of the gap between actual and trend unemployment rates over 
time shows that the recent magnitude of the gap is comparable to that at the past two labor market peaks, the years 2000 and 2006-07, suggesting no tighter labor markets.

These findings, in combination with the job finding rate accounting for less of the decline in unemployment than is usual at this late stage of the business cycle expansion, might help explain moderate wage growth and limited price inflation despite a historically low unemployment rate.

Our concept of trend unemployment corresponds to the natural rate of unemployment defined as the unemployment rate that prevails once the economy has fully adjusted to business cycle shocks. Our estimates are consistent with other recent work. In Hornstein and Kudlyak (2019) we find a similar decline in the trend unemployment rate, estimated from state-space models of the unemployment rates and labor force participation rates of different age-gender-education groups. Tuzemen (2019) finds that ongoing demographic and technological changes could lower the trend unemployment rate to 4.4 percent by the end of 2022. Our results on the important role of the long-run decline in the inflow rate for the secular decline of the unemployment rate trend are consistent with the findings of Tasci (2012) and Crump, Eusepi, Giannoni and Şahin (2019).

The rest of the paper is structured as follows. Section 1 describes an approximation of the unemployment rate as a function of the flow rates between labor market states. Section 2 examines which changes in flow rates contribute the most to the current low unemployment rate. Section 3 constructs an unemployment rate trend from the trends in the flow rates. Section 4 separates out the contributions of trend and cycle in flow rates to the recent changes in the unemployment rate. Section 5 concludes.

\section{Inflow-Outflow Model of the Unemployment Rate}

The unemployment rate changes over time when more or less people flow into unemployment from other labor market states - employment and out of the labor force - than people flow out of unemployment to these other states. The flows in and out of unemployment are determined by the number of people in the different labor market states and the rates at which they flow between these states. We follow an established approach that accounts for cyclical and trend changes in the unemployment rate through an analysis of the changes in the cyclical and trend components of the flow rates, e.g. Shimer (2005). In particular, we use a feature of relatively high flow rates in the U.S. labor market that allows us to approximate the unemployment rate path over time through its steady state path implied by the flow rates. 
We can express changes in unemployment and in employment as functions of inflows and outflows, which are in turn determined by the stocks of the unemployed, $U_{t}$, employed, $E_{t}$, and those OLF, $N_{t}$, and the rates at which people flow between these states. The instantaneous change in unemployment is

$$
d U_{t}=\lambda_{t}^{E U} E_{t}+\lambda_{t}^{N U} N_{t}-\left(\lambda_{t}^{U E}+\lambda_{t}^{U N}\right) U_{t}
$$

and the instantaneous change in employment is

$$
d E_{t}=\lambda_{t}^{U E} U_{t}+\lambda_{t}^{N E} N_{t}-\left(\lambda_{t}^{E U}+\lambda_{t}^{E N}\right) E_{t}
$$

where $\lambda_{t}^{A B}$ is the flow rate from labor market state $A$ to state $B, A, B=E, U, N ; A \neq B$.

Equation (1) defines the change in the stock of the unemployed as the inflow from employment plus the inflow from OLF minus the outflow to employment and OLF. Each flow is the product of the flow rate from the originating state to the destination state and the originating stock. Equation (2) does the same for the stock of employed people.

For given flow rates, the labor market has attained a steady state when the inflows and outflows balance, and the number of people in different labor market states does not change. In the U.S., labor market flow rates tend to be high enough such that for fixed flow rates the unemployment rate converges to its steady state quickly (Petrongolo and Pissarides (2008)). Thus, the unemployment rate, $u_{t}$, is well approximated by its steady state value, $\bar{u}_{t}$ :

$$
u_{t} \equiv \frac{U_{t}}{U_{t}+E_{t}} \simeq \bar{u}_{t} \equiv \frac{\bar{U}_{t}}{\bar{U}_{t}+\bar{E}_{t}}
$$

where $\bar{U}_{t}$ and $\bar{E}_{t}$ are steady-state values of stocks obtained from equation (1) and equation (2) when $d U_{t}=d E_{t}=0.1$

The steady state unemployment rate can be expressed as a function of the six flow rates between unemployment, employment and OLF as follows:

$$
\bar{u}_{t}=\frac{\lambda_{t}^{E U} \lambda_{t}^{N U}+\lambda_{t}^{E U} \lambda_{t}^{N E}+\lambda_{t}^{E N} \lambda_{t}^{N U}}{\lambda_{t}^{E U} \lambda_{t}^{N U}+\lambda_{t}^{E U} \lambda_{t}^{N E}+\lambda_{t}^{E N} \lambda_{t}^{N U}+\lambda_{t}^{U E} \lambda_{t}^{N U}+\lambda_{t}^{U E} \lambda_{t}^{N E}+\lambda_{t}^{U N} \lambda_{t}^{N E}} .
$$

We construct the empirical counterparts of the instantaneous flow rates in equation (4) using the monthly CPS micro data from January 1976 to December 2019. We match individuals in adjacent monthly files, and calculate the month-to-month transition probabilities between labor market states. We then seasonally adjust these monthly flow probabilities, and calculate instantaneous flow rates from the probabilities using the procedure described

\footnotetext{
${ }^{1}$ By definition the stock of OLF, $N_{t}$, in equation (1) and equation (2) is total population less those employed and unemployed, $E_{t}$ and $U_{t}$. The steady state values, $\bar{E}$ and $\bar{U}$, are then proportional to population, and the steady state unemployment rate depends only on the flow rates in equation (1) and equation (2).
} 
in Shimer (2012). We convert monthly series to quarterly averages to smooth the data. We work with the steady state unemployment rate constructed from equation (4) using the instantaneous flow rates.2

\section{Which Flow Rates Best Explain the Current Low Unemployment Rate}

\subsection{How the Current Flow Rates Compare to the Past}

The unemployment rate declines in expansions because exit rates from unemployment increase and entry rates into unemployment decrease. Currently, exit rates from unemployment are comparable with their historical levels, but entry rates to unemployment are at their lowest levels in four decades.

Figure 1 displays the six flow rates between employment, unemployment, and OLF. Any flow rate represents outflows from one state and inflows into another state. Since our focus is on the unemployment rate, and since we will argue that the unemployment rate is mainly determined by the flow rates into and out of unemployment, in the following we will sometimes talk about inflow rates into unemployment, that is, flow rates from employment and OLF to unemployment, and outflow rates from unemployment, that is, flow rates from unemployment to employment and OLF, simply as inflow and outflow rates.

Outflow rates from unemployment to employment (UE) and to OLF (UN) increase in expansions and decline in recession, and they do not display a noticeable trend, (Figure 1 . panel a). Currently, as of 2019Q4, both outflow rates are not unusually high. In fact, the UE rate is still below its 2007 peak.

By contrast, inflow rates to unemployment from employment (EU) and from OLF (NU) decline in expansions and increase in recessions, and they exhibit a noticeable downward trend, especially the EU rate, (Figure 1, panel b). At the end of 2019, the inflow rates to unemployment are at their lowest levels for the sample period.

Finally, the flow rates between employment and OLF (EN and NE) impact the unemployment rate indirectly via changes in the stocks of the employed and OLF. These flow rates are of similar magnitude as the unemployment inflow rates, and like the inflow rates, they apply to large pools such that the implied flows can be substantial. Similarly to the job finding rate from unemployment, the job finding rate from OLF (NE) has not yet reached its pre-recession peak in 2019Q4 (Figure 1, panel c).

\footnotetext{
${ }^{2}$ Figure A.1 in the Appendix shows that the actual unemployment rate from the BLS is well approximated by the implied steady-state unemployment rate.
} 
Figure 1: Flow Rates between Labor Market States

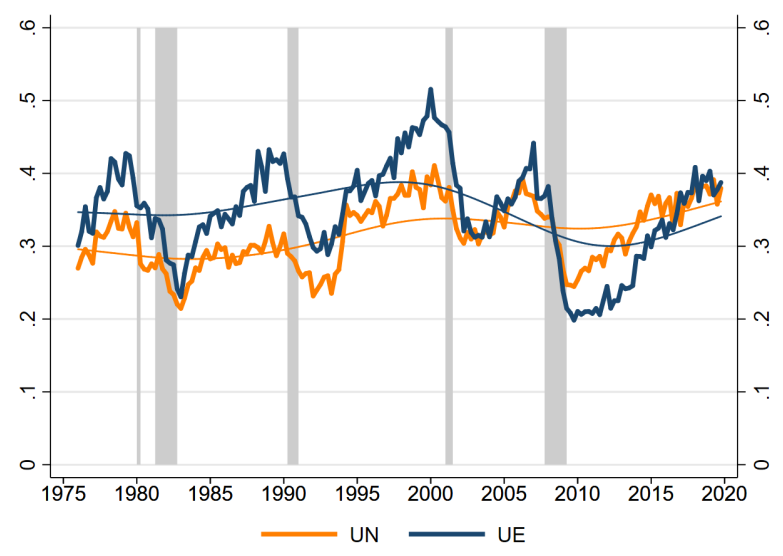

(a) Unemployment outflow rates

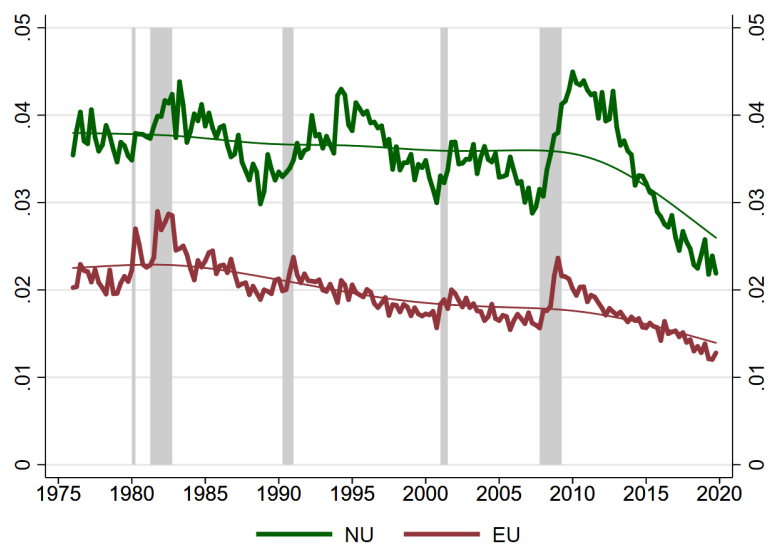

(b) Unemployment inflow rates

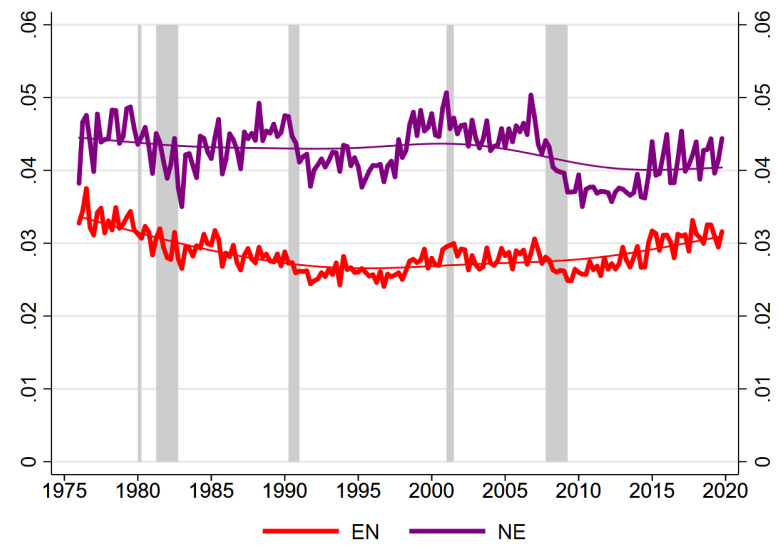

(c) Flow rates between employment and OLF

Note: Quarterly averages of monthly SA series, 1976Q1 - 2019Q4. Shaded areas represent NBER recessions. 
To summarize, the current unemployment outflow rates are not unusually high, but the current unemployment inflow rates are unusually low. This suggests that the current historically low unemployment rate most likely stems from low unemployment inflow rates. The next section seeks to quantify the contribution of the different flow rates.

\subsection{Which Flow Rates Drive Current Unemployment}

We construct six counterfactual unemployment rates using equation (4). Each counterfactual unemployment rate is calculated by holding five flow rates fixed at their sample means and using the actual time path for the sixth flow rate. This counterfactual exercise provides insights into how important each flow rate is for movements in the unemployment rate, similar to an accounting decomposition. It does not, of course, reveal what underlying economic forces drive the different flow rates.

Figure 2 shows the actual and counterfactual unemployment rates for unemployment inflow rates in panel (a), unemployment outflow rates in panel (b), and flow rates between employment and OLF in panel (c). Each counterfactual is labeled by the time-varying flow rate. All series are shown as deviations from their sample means.

Comparing the counterfactual unemployment rates for 2019 across panels (a), (b) and (c) in Figure 2, we find that the counterfactual unemployment rates driven by the unemployment inflow rates from employment and OLF (panel b) show the largest downward deviations from their means - about 1 percentage point. That is, the largest contributions to the low current unemployment rate stem from the changes in the unemployment inflow rates.

By comparison, the counterfactual unemployment rates driven by the unemployment outflow rates to either employment or OLF each deviate approximately 0.5 percentage points from their means (panel a). This differs from past recoveries. For past business cycle peaks, the unemployment rate was low mainly because of high job finding rates, that is, unemployment outflow rates to employment (blue line in panel a).

To summarize, the counterfactual exercises in Figure 2 confirm the conjecture from the previous section, that the current low unemployment rate stems primarily from historically low unemployment inflow rates (EU and NU) and not from unusually high unemployment outflow rates (UE and $\mathrm{NE}$ ).

We next decompose the unemployment rate into trend and cycle components based on the trends of the six flow rates. This helps to separate out the contributions of trend and cycle to the current unemployment rate. 
Figure 2: Actual and Counterfactual Unemployment Rate, Deviations from Sample Mean
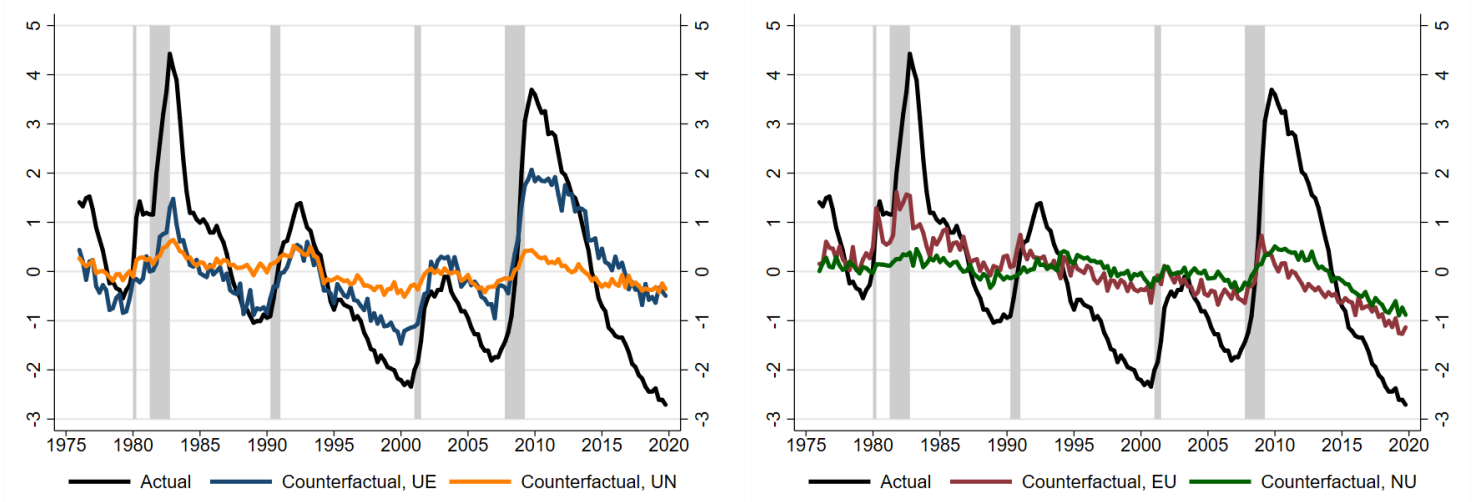

(a) Counterfactuals with varying unemployment (b) Counterfactuals with varying unemployment outflow rates inflow rates

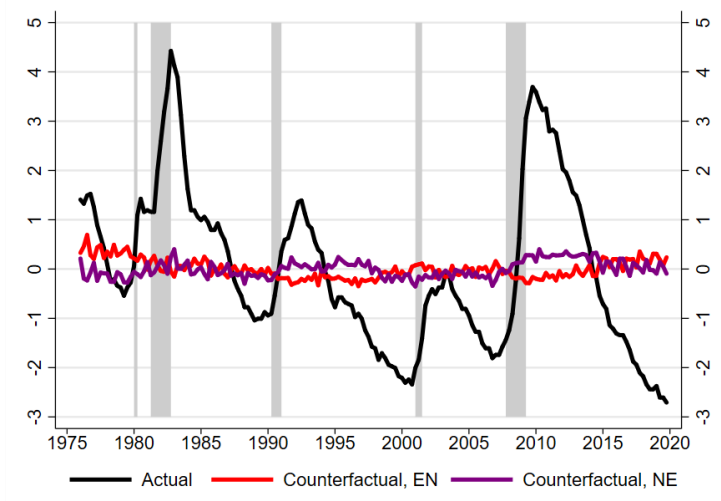

(c) Counterfactuals with varying flow rates between employment and OLF

Note: The counterfactual unemployment rate is constructed using equation (3) by holding five flow rates fixed at their sample means while using the actual time path for the sixth flow rate. Each counterfactual is labeled by the time-varying flow rate. The panels display the series in deviations from their sample means, 1976Q1 - 2019Q4. 


\section{Trend and Cycle of the Unemployment Rate}

\subsection{Trend Unemployment from Trend Flow Rates}

We construct the trend unemployment rate, $u_{t}^{\text {trend }}$, by replacing the actual flow rates in the steady state equation (4) with the trend flow rates, $\lambda_{t}^{A B, t r e n d}$. Our baseline specification of the trend flow rates applies the Hodrick-Prescott filter (Hodrick and Prescott (1997); hereafter, HP) with a smoothing parameter of $10^{5}$ to the quarterly flow rates $3^{4}$

Figure 1 displays the HP-trends of the actual flow rates between employment, unemployment, and OLF as thin smooth lines. The main takeaway from the flow rate trends in Figure 1 is that the unemployment inflow rates have been on a downward trend, especially the inflow rate from employment. By contrast, the trend of the unemployment outflow rates has remained quite stable throughout the sample period.

Figure 3 plots the unemployment rate, as well as its trend constructed from the flow rate trends following equation (4), and the cycle, that is, the deviations of actual from trend. In 2019Q4, the actual unemployment rate, at 3.5 percent, is a little less than 1 percentage point below its estimated trend at 4.4 percent.

Having estimated the trend in unemployment, we can now decompose the difference in unemployment between two points in time into the change due to the trend and the remainder (i.e., "cycle"). Table 1 summarizes the differences in the unemployment rate level, trend, and cycle between 2019 and the two previous business cycle peaks (2000 and 2007).

The key takeaway from Table 1 is that relative to the previous cyclical peaks in 2000 and 2007 the lower unemployment rate in 2019 is more than fully accounted for by its declining trend. Specifically, the unemployment rate in 2019 is 0.86 percentage points lower than in 2007, while its trend in 2019 is 1.19 percentage points lower than in 2007. Similarly, the unemployment rate in 2019 is 0.30 percentage points lower than in 2000, while its trend in 2019 is 0.60 percentage points lower. In other words, the cyclical deviation from trend in the current labor market is still less than it was in the labor markets of 1999 and 2007.

Of course, our calculation of the current cyclical unemployment rate gap depends on our definition of the trend. And the future evolution of the unemployment rate will affect the estimates of the current trend and cyclical unemployment rate. For example, if the U.S. economy were to enter a recession in the near future and the unemployment rate were to

\footnotetext{
${ }^{3}$ This value of the parameter helps alleviate the well-known concerns that the HP filter attributes most of the end-of-the-sample variation of a time series to the trend, e.g. Shimer (2005). We check the robustness of our results to alternative definitions of the trend. For this purpose we use larger and smaller values of the smoothing parameter for the HP filter, and also consider the Hamilton (2018) filter. The results are in the Appendix.

${ }^{4}$ For an alternative approach of deriving the trends from the flow rates and using the steady-state relationship, see Tasci (2012).
} 
Figure 3: Unemployment Rate, Long-Run Trend and Cycle

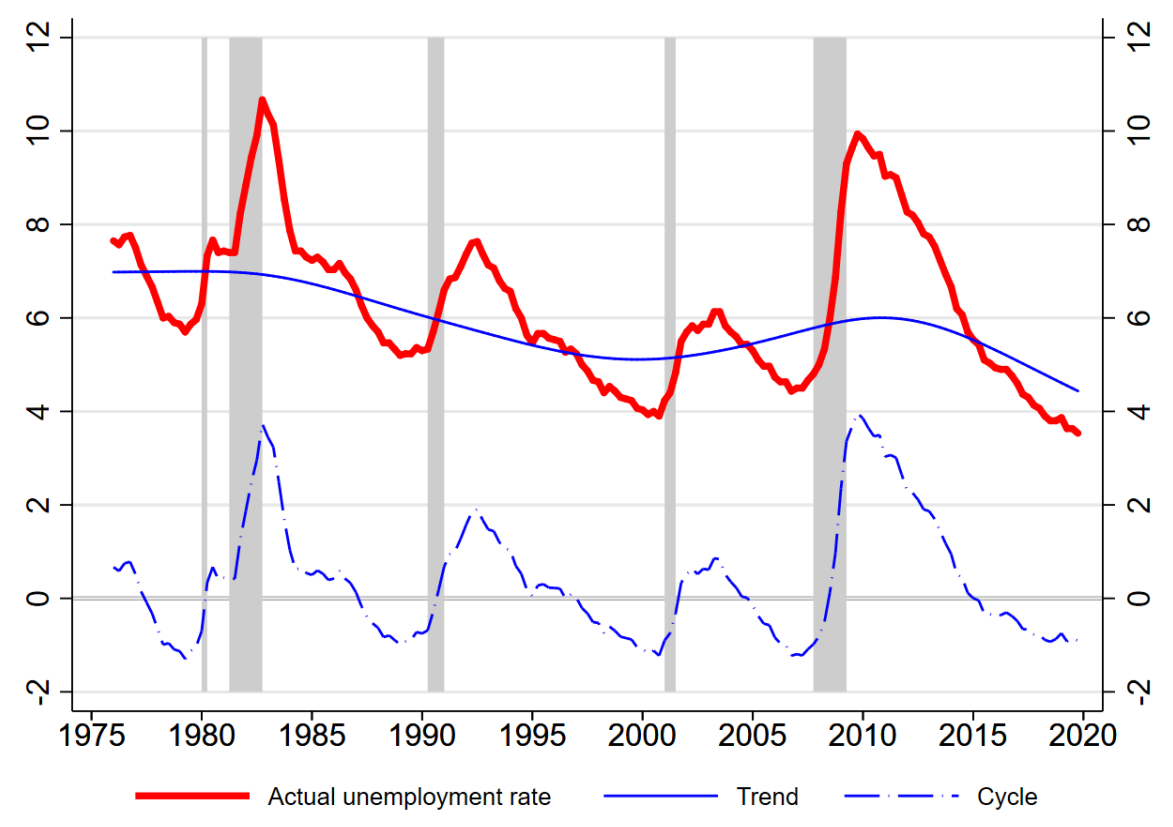

Note: The trend is the steady state approximation of the unemployment rate using the trends of the flow rates. The flow rate trends are calculated using the HP filter with a smoothing parameter of $10^{5}$. The cycle is the difference between actual and trend unemployment. Quarterly SA series, 1976Q1 - 2019Q4. 
Table 1: Trend and Cycle in Unemployment in 2019 Relative to 2000 and 2007

\begin{tabular}{r|rr|rr|rr}
\hline \hline & \multicolumn{2}{|c|}{ Actual } & \multicolumn{2}{c|}{ Trend } & \multicolumn{2}{c}{ Cycle } \\
\cline { 2 - 7 } & Value $\begin{array}{c}\text { Relative } \\
\text { to 2019 }\end{array}$ & Value $\begin{array}{r}\text { Relative } \\
\text { to 2019 }\end{array}$ & Value $\begin{array}{r}\text { Relative } \\
\text { to 2019 }\end{array}$ \\
\hline 2000 & 3.97 & 0.30 & 5.12 & 0.60 & -1.15 & -0.30 \\
2007 & 4.53 & 0.86 & 5.71 & 1.19 & -1.19 & -0.34 \\
2019 & 3.67 & & \multicolumn{2}{|c|}{4.52} & & -0.85 \\
\hline \hline
\end{tabular}

Note: For 2007, the rates are the average over 2006Q4 - 2007Q3. For 2000 and 2019, the rates are the annual averages of quarterly series.

increase, then our baseline HP-filter would revise up the trend for the current period and increase the magnitude of the current cyclical gap. For an HP-filter with a larger smoothing parameter, as discussed in the Appendix, the trend is less sensitive to these kinds of changes in the underlying data, but this would also apply to trend calculations for earlier episodes such as 1999 and 2007. Overall, the relative magnitudes of the cyclical gaps in 2000, 2007, and 2019, remain similar for this alternative trend definition.

\subsection{How the Trend Unemployment Relates to $\mathrm{u}^{*}$}

How does the concept of the trend in the unemployment rate studied here relate to the concept of the "natural rate of unemployment"?

A common definition of the natural rate of unemployment $\left(\mathrm{u}^{*}\right)$ is the unemployment rate that prevails once the economy has fully adjusted to business cycle shocks. Our concept of trend unemployment fits with this definition of the natural rate. Another definition relates the natural rate of unemployment to the Philips curve, and defines it as the unemployment rate at which inflation does not change..$^{5}$

Other measures of the natural rate of unemployment that are unrelated to inflation include the CBO estimate, CBO (2020), or Hornstein and Kudlyak (2019). Both of these natural rate definitions calculate trend unemployment adjusted for demographic changes, and they yield trend unemployment estimates for 2019 that are very close to the estimate in this paper.

In contrast, studies that estimate a Philips-curve based natural unemployment rate typically find values lower than the one in this paper for the current period (see, for example, Crump et al. (2019) and a discussion in Petrosky-Nadeau and Valletta (2019)). Since in the

\footnotetext{
${ }^{5}$ For example, Crump et al. (2019) distinguish between a long-run $\mathrm{u}^{*}$, the unemployment rate trend unrelated to inflation, and a short-run $\mathrm{u}^{*}$, the unemployment rate consistent with a non-accelerating inflation rate.
} 
recent past inflation has not been very responsive to changes in the unemployment rate, and since current inflation remains low, Philips-curve based natural rates cannot differ too much from the actual unemployment rate. The details, however, depend on the modelling of the inflation expectations and other factors, which Davis (2019) argues are more important for assessing current and near-term inflation pressures.

\section{Contribution of Flow Rates to the Recent Change in Unemployment}

We now evaluate the contributions of the different flow rates to the change in trend unemployment and the cyclical movements of unemployment.

\subsection{Contribution to the Trend Unemployment}

How much did each flow rate contribute to the fall in the trend component of the unemployment rate between 2007 and 2019? To answer this question, we construct the counterfactual trend unemployment rates for 2019 by fixing five flow rate trends at their 2007 level and allowing one flow rate trend to vary (Table 2, Column 2). We then calculate how much of the change in the unemployment rate trend between 2007 and 2019 can be accounted for by each of the flow rate trends. Columns 3 of Table 2 shows the results in percent.

The key takeaway from Table 2 is that between 2007 and 2019, almost the entire decline in the unemployment rate trend is driven by the decline in the trends of the unemployment inflow rates, EU and NU.

\subsection{Contribution to the Cyclical Unemployment}

We now construct the contribution of each of the six flow rates to the cyclical component of the unemployment rate. This can be constructed for each quarter in our sample. We can then compare the current period to the previous business cycle peaks.

Figure 4, panel (a) shows the cyclical unemployment rate (which is the difference between the actual unemployment rate and the estimated trend displayed in Figure 3) and the contribution of the EU (blue line) and NU (yellow line) to the cyclical unemployment rate. Panels (b) and (c) show the contributions of the remaining four rates ${ }^{6}$

\footnotetext{
${ }^{6}$ The contribution of each flow rate to the cyclical unemployment rate is constructed analogous to Section 2. For each flow rate we construct a counterfactual steady state unemployment rate path for which we use the actual flow rate path of the flow rate under consideration and the trends for the remaining flow rates in equation (4). The cycle contribution of the flow rate is the difference between the counterfactual and the trend unemployment rate. Since equation (4) is non-linear, the cycle contributions of the six rates do not necessarily add up to the overall cyclical unemployment.
} 
Figure 4: Cyclical Unemployment Rate and Counterfactuals Driven by Different Flow Rates

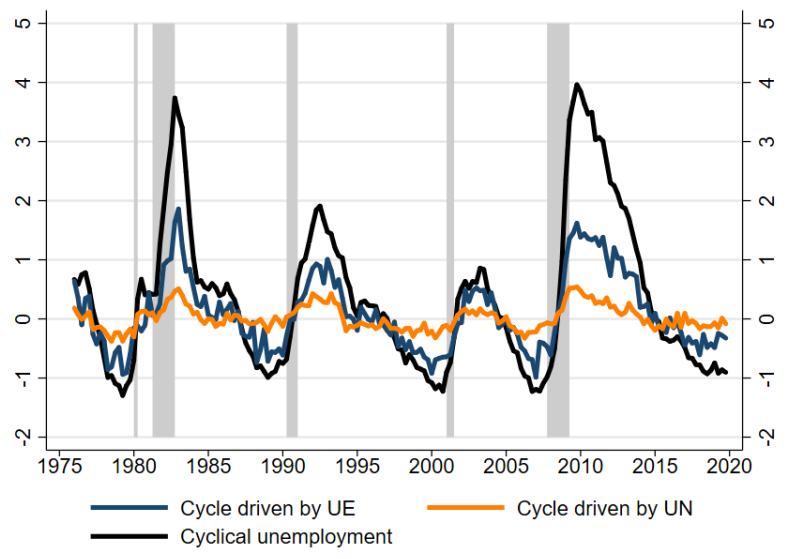

(a) Unemployment outflow rates

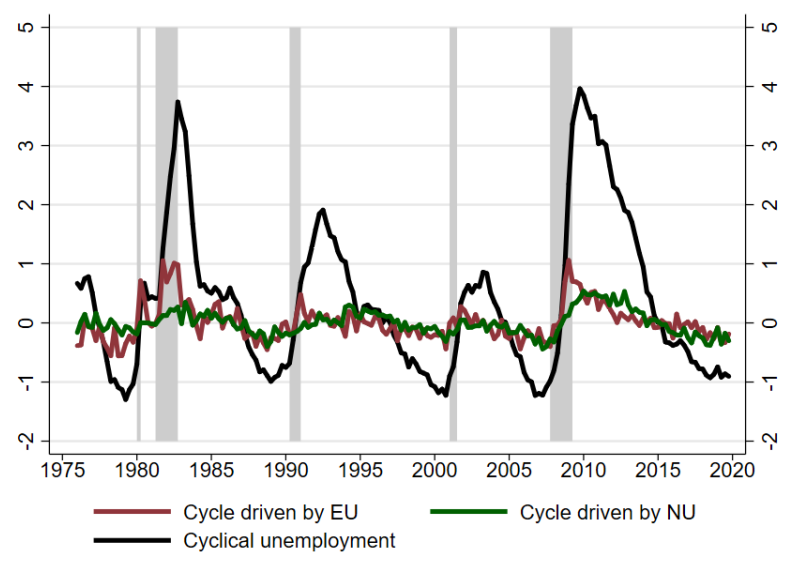

(b) Unemployment inflow rates

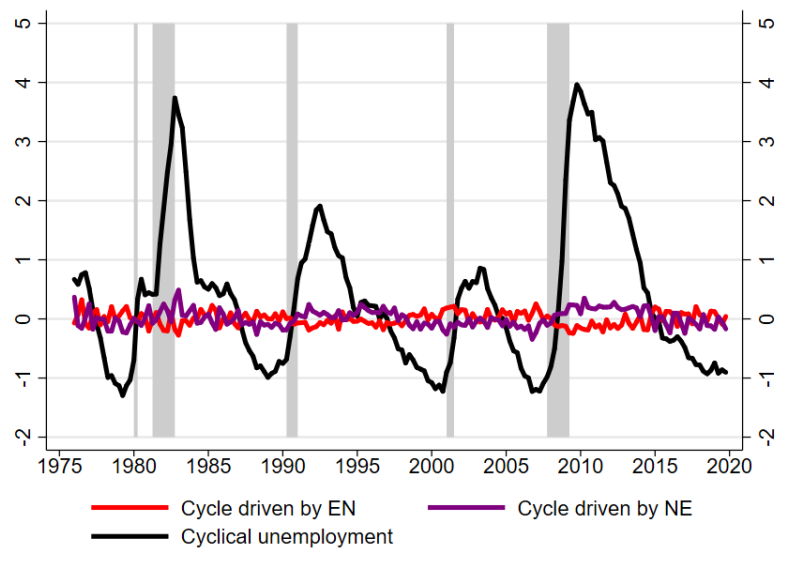

(c) Flow rates between employment and OLF

Note: Quarterly SA series, 1976Q1 - 2019Q4. 
Table 2: Contribution of Flow Rates Trends to the Change in the Unemployment Rate Trend, 2007 and 2019

\begin{tabular}{c|cc|c}
\hline \hline & \multicolumn{2}{|c|}{ Unemployment trend, pp } & Contribution to the change in \\
& 2007 & 2019 & unemployment rate trend, \% \\
\hline & 1 & 2 & 3 \\
\hline \begin{tabular}{l|l} 
Estimated trend \\
Counterfactual (5 flow. rates
\end{tabular} & 5.71 & 4.52 & \\
$\begin{array}{l}\text { trends fixed at the base period, 1 } \\
\text { unfixed): }\end{array}$ & & & \\
EU & & 5.03 & 57 \\
NU & & 5.11 & 51 \\
UE & & 5.60 & 9 \\
UN & & 5.53 & 15 \\
NE & & 5.80 & -8 \\
EN & & 5.98 & -23 \\
\hline \hline
\end{tabular}

Note: For 2007, the rates are the average over 2006Q4 - 2007Q3. For 2000 and 2019, the rates are the annual averages of quarterly series.

Figure 4 shows that most of the time the job finding rate (UE-flows), and in recessions also the job-loss rate (EU-flows), are the most important sources of cyclical unemployment changes..$^{7}$ Cyclical variations in flow rates that involve movement from and to OLF tend to contribute less to cyclical unemployment 8 In contrast, at the end of 2019, the role of the job finding rate in driving the decline in the cyclical unemployment is smaller.

\section{Conclusions}

To summarize, the current unusually low unemployed rate cannot be attributed to a particularly high job finding rate, but rather results from unusually low inflow rates into unemployment that reflect a long-run downward trend.

Comparison of the actual and trend unemployment rates over time shows that the recent gap between them is similar to the gap measured as of the past two labor market peaks (years 2006-07 and 2000). This suggests that the labor market in 2019 is no tighter than

\footnotetext{
${ }^{7}$ For studies of the contribution of inflows and outflows to the dynamics of unemployment see Elsby, Michaels and Solon (2009), Fujita and Ramey (2009), and Portugal and Rua (2020).

${ }^{8}$ See, e.g., Shimer (2005) and Shimer (2012).
} 
during the previous peaks. These findings might help explain moderate wage growth and limited price inflation despite a historically low unemployment rate.

Our approach accounts for the low unemployment rate through trends in the flow rates, but we do not explain why flow rates changed. Recent candidate explanations for the decline in the inflow rates to unemployment include demographic and other structural factors. For example, Crump et al. (2019) argue that the increase in labor force attachment of females, the decline in job destruction and reallocation intensity, and the dual aging of workers and firms drive the long-run decline in the unemployment inflow rate. Pries and Rogerson (2019) argue that improved match quality is an important driver of the secular decline in the employment-to-unemployment inflow rate. Population aging, disability and opioid crisis might explain the trend decline in OLF-to-unemployment inflow rate (Barnichon and Nekarda (2012), Barnichon and Mesters (2018)).

\section{References}

Barnichon, Regis and Christopher J. Nekarda, "The Ins and Outs of Forecasting Unemployment: Using Labor Force Flows to Forecast the Labor Market," Brookings Papers on Economic Activity, 2012, pp. 83-117.

_ _ and Geert Mesters, "On the Demographic Adjustment of Unemployment," Review of Economics and Statistics, 2018, 100 (2), 219-231.

CBO, "Natural Rate of Unemployment (Long-Term) [NROU]," Technical Report, U.S. Congressional Budget Office Jan 2020. Data retrieved from FRED, Federal Reserve Bank of St. Louis: https://fred.stlouisfed.org/series/NROUST.

Crump, Richard K., Stefano Eusepi, Marc Giannoni, and Ayşegül Şahin, "A Unified Approach to Measuring u*," Brookings Papers on Economic Activity, 2019, pp. 143-213.

Davis, Steve, "Comment on "A Unified Approach to Measuring u*"," Brookings Papers on Economic Activity, 2019, pp. 215-223.

Elsby, Michael W. L., Ryan Michaels, and Gary Solon, "The Ins and Outs of Cyclical Unemployment," American Economic Journal: Macroeconomics, January 2009, 1 (1), $84-110$.

Fujita, Shigeru and Garey Ramey, "The Cyclicality of Separation and Job Finding Rates," International Economic Review, 2009, 50 (2), 415-430. 
Hamilton, James D., "Why You Should Never Use the Hodrick-Prescott Filter," Review of Economics and Statistics, 2018, 100 (5), 831-843.

Hodrick, Robert J., "An Exploration of Trend-Cycle Decomposition Methodologies in Simulated Data," 2020. Mimeo, Columbia University.

_ _ and Edward C. Prescott, "Postwar US Business Cycles: an Empirical Investigation," Journal of Money, Credit, and Banking, 1997, 29 (1), 1-16.

Hornstein, Andreas and Marianna Kudlyak, "Aggregate Labor Force Participation and Unemployment and Demographic Trends," 2019. FRB San Francisco Working Paper No. 19-07.

Petrongolo, Barbara and Christopher A. Pissarides, "The Ins and Outs of European Unemployment," American Economic Review: Papers $\&$ Proceedings, 2008, 98 (2), 256-262.

Petrosky-Nadeau, Nicolas and Robert G. Valletta, "Unemployment: Lower for Longer?," FRBSF Economics Letter, 2019, 2019-21.

Portugal, Pedro and Antonio Rua, "How the Ins and Outs Shape Differently the U.S. Unemployment over Time and across Frequencies," European Economic Review, 2020, 121, 1-13.

Pries, Michael J. and Richard Rogerson, "Declining Worker Turnover: the Role of Short Duration Employment Spells," 2019. Working Paper, Princeton University.

Schuler, Yves S., "On the Cyclical Properties of Hamilton's Regression Filter," 2018. Deutsche Bundesbank Discussion Paper No. 03/2018.

Shimer, Robert, "The Cyclical Behavior of Equilibrium Unemployment and Vacancies," American Economic Review, 2005, 95 (1), 25-49.

_ " "Reassessing the Ins and Outs of Unemployment," Review of Economic Dynamics, 2012, 15 (2), 127-148.

Tasci, Murat, "The Ins and Outs of Unemployment in the Long Run: Unemployment Flows and the Natural Rate," 2012. Federal Reserve Bank of Cleveland, working paper no. $12-24$.

Tuzemen, Didem, "Job Polarization and the Natural Rate of Unemployment in the United States," Economics Letters, 2019, 175, 97-100. 


\section{Appendix}

Figure A.1 displays the actual unemployment rate and the steady state unemployment rate constructed from equation (4) using the quarterly instantaneous flow rates from Figure 1.

Figure A.2 displays the estimated trend and cycle for the six flow rates for the baseline HP-smoothing parameter, $10^{5}$ as in Shimer (2005), as well as results for lower and higher values of the smoothing parameter - a lower smoothing parameter value of 1,600 (typically used for quarterly data), and a higher parameter of $10^{6}$ (a value much higher than typically used in the literature). For a smoothing parameter of 1,600, we find that the trend is almost equal to the actual series values in the last few years of the sample. For a smoothing parameter of $10^{6}$, the trend is almost linear, and the filter attributes a larger fraction of the end-of-the-sample variation to the cycle than the baseline filter does.

Figure A.3 displays the estimated trend and cycle for the two flow rates between unemployment and employment, using the Hamilton (2018) filter which is designed to be immune to the end-of-the-sample issues of the HP-filter. Compared with the HP-filters, the trend from the Hamilton filter indeed behaves very differently at the end of the sample for the two series. On the one hand, the Hamilton filter essentially puts the trend at the actual values for the unemployment outflow rate EU, like the HP-filter with smoothing parameter 1,600. On the other hand, the Hamilton filter puts the trend consistently above the actual values for the unemployment inflow rate, whereas the HP-filters with large smoothing parameters put the trend below the actual data. Finally, throughout the sample, the Hamilton trend differs substantially from the HP trend: its trend tends to be much closer to the actual values than the trends from either of the HP-filters. This is consistent with Schuler (2018) who argues that the Hamilton filter falls short of reproducing the chronology of U.S. business cycles (see also Hodrick (2020)).

Figure A.4 displays the unemployment rate trends for the alternative filters. The smaller the HP-smoothing parameter, the larger is the portion of the end-of-sample deviation that is attributed to trend (panel a). If the filters are applied directly to the unemployment rate series (black lines in panels a and b), the estimated trends are about 0.3-0.5pp higher than the trend obtained from using equation (4) after applying the filters to flow rates (blue lines in panels $\mathrm{a}$ and $\mathrm{b})$. At the end of the sample, the trend from the HP filter with a smoothing parameter $10^{5}$ and the trend from the Hamilton filter are similar (panel c).

Figure A.5 displays the cyclical unemployment rate deviations from trend for all four filters. All, but the HP-filter with the 1,600-smoothing parameter, display a noticeable cyclical gap for 2019Q4 that is of a similar magnitude to the gap at the two previous cyclical peaks in 2000 and 2007. 
Figure A.1: Unemployment Rate and Its Steady State Approximation

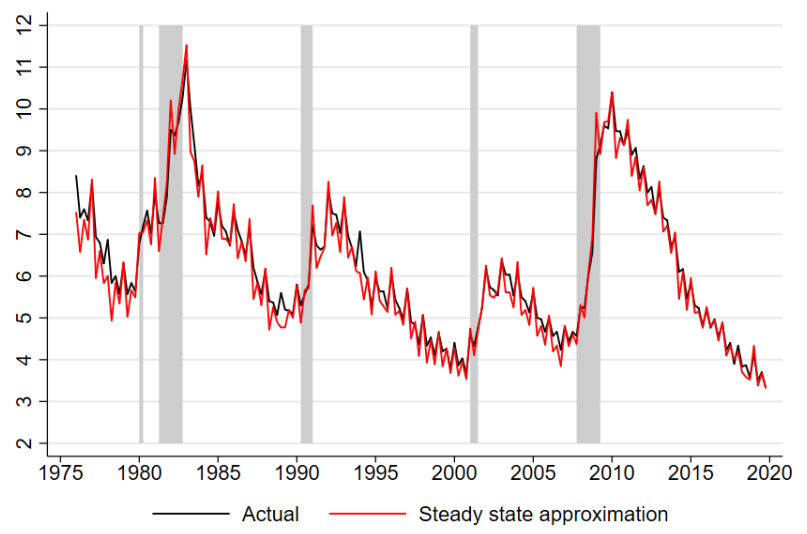

Note: Quarterly NSA series, 1976Q1-2019Q4. Shaded areas denote NBER recessions. 
Figure A.2: Flow Rates, Trend and Cycle

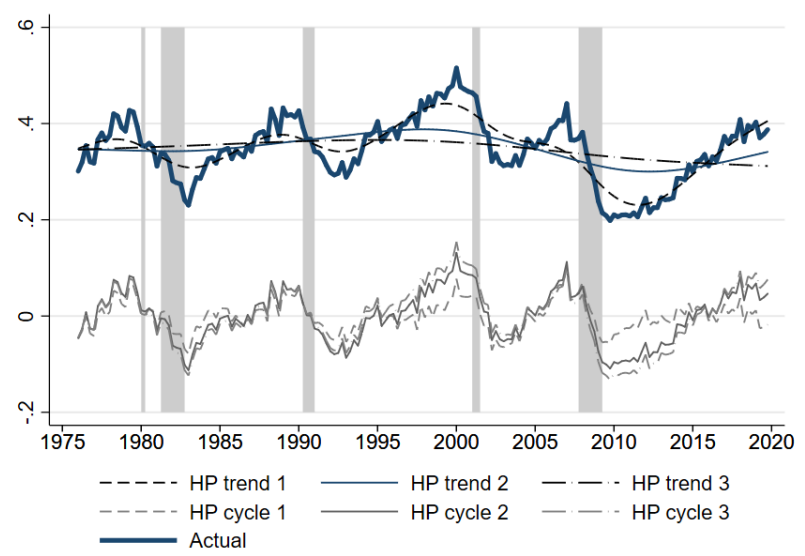

(a) UE

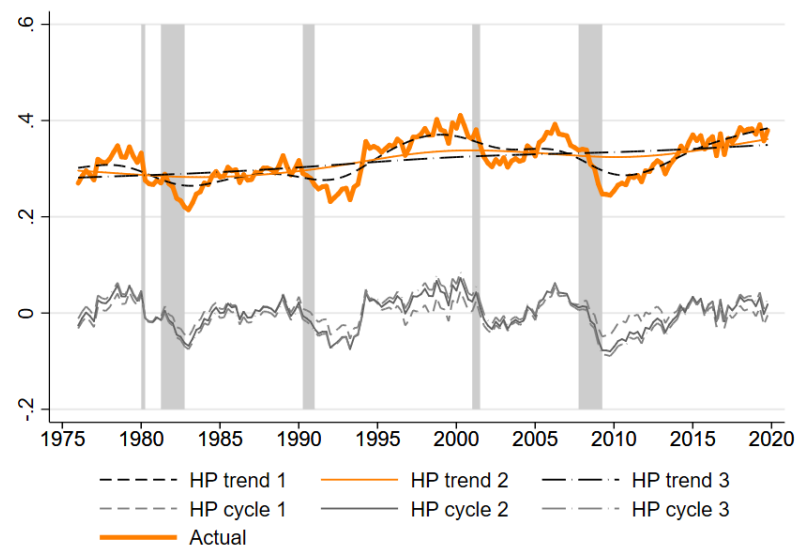

(b) UN

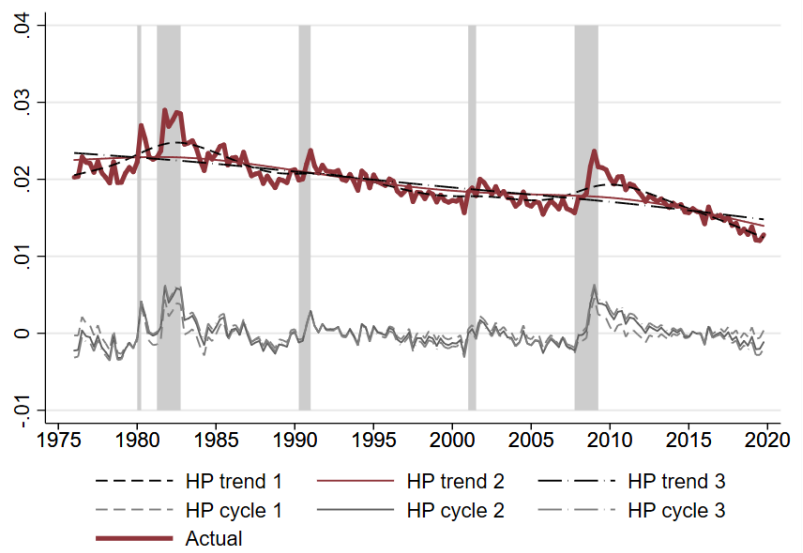

(c) $\mathrm{EU}$ 


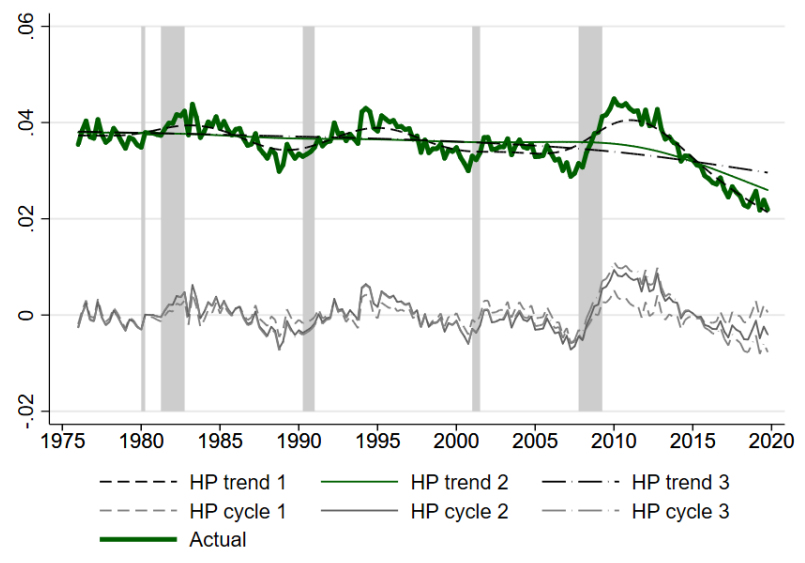

(d) NU

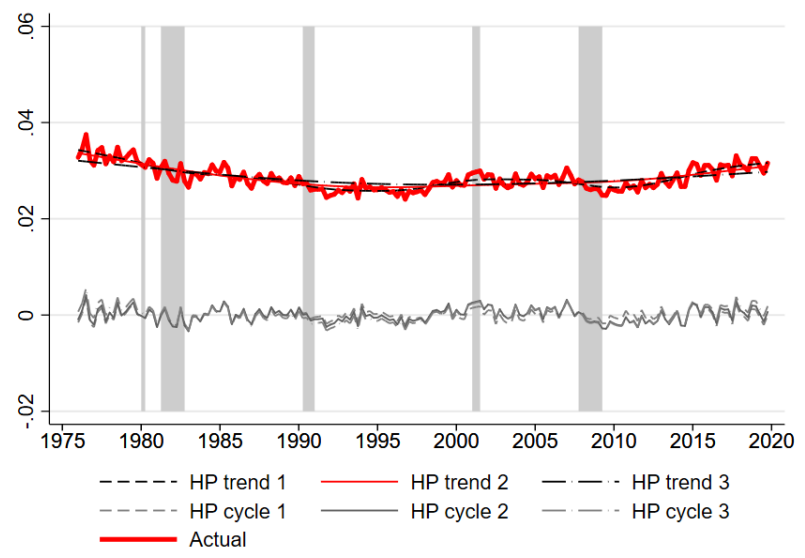

(e) EN

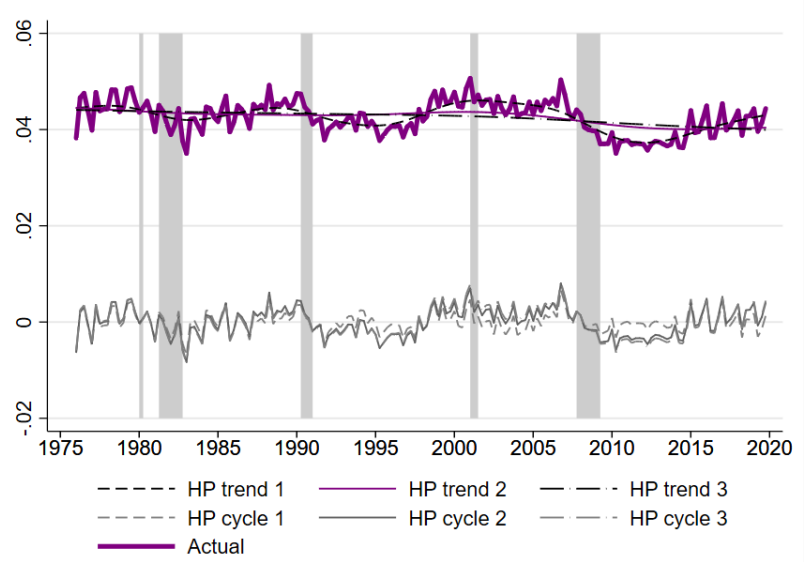

(f) $\mathrm{NE}$

Note: Figures show three HP filters with smoothing parameter 1,600 (HP 1), $10^{5}$ (HP 2) and $10^{6}$ (HP 3) applied to quarterly data, 1976Q1 - 2019Q4. 
Figure A.3: Selected Flow Rates, Trend and Cycle, Hamilton filter

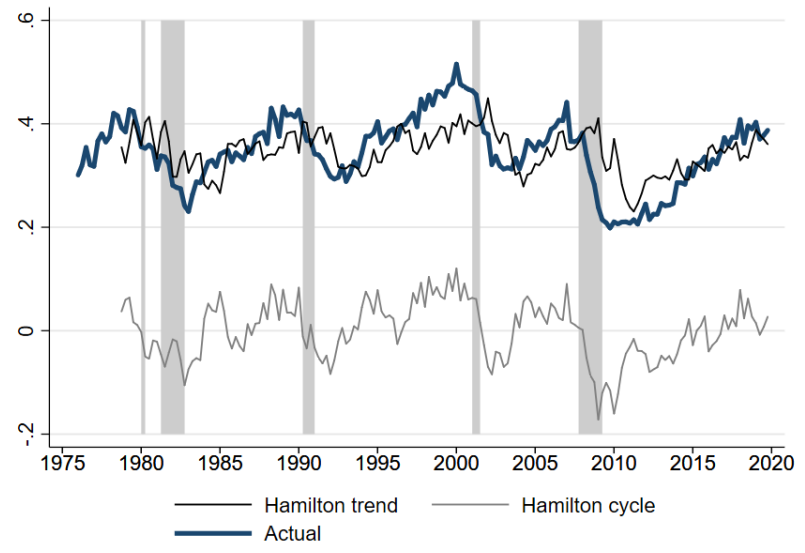

(a) UE

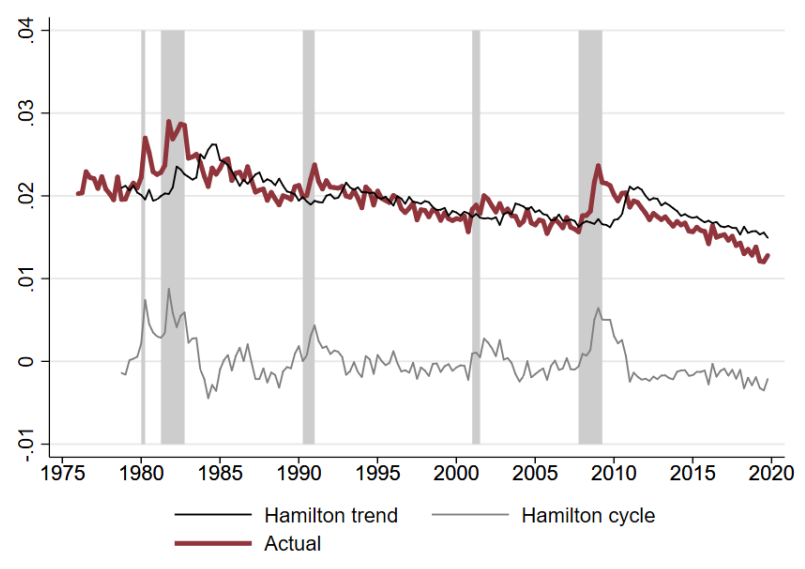

(b) EU

Note: Quarterly SA series, 1976Q1 - 2019Q4. 
Figure A.4: Unemployment Rate and Its Trend, Various Filters
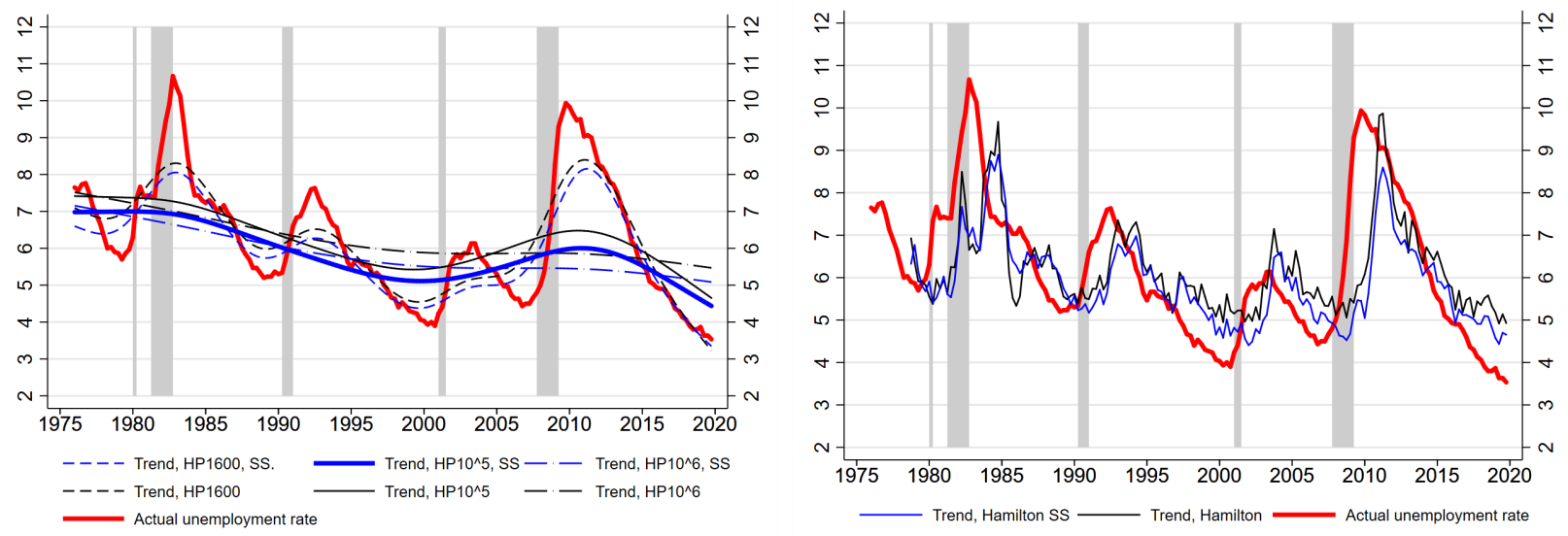

(a) HP-filter trend, from the actual unemployment (b) Hamilton trend, from the actual unemployment rate and from the trends in flow rates rate and from the trends in flow rates

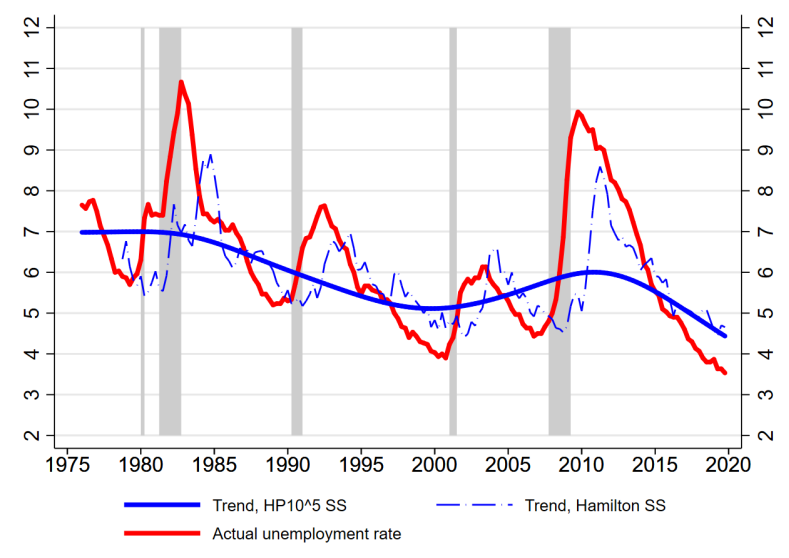

(c) HP-filter with $\lambda=10^{5}$ trend and Hamilton trend, from the trends in the flow rates

Note: Quarterly SA series, 1976Q1 - 2019Q4. 
Figure A.5: Cyclical Unemployment Rate for Various Filters

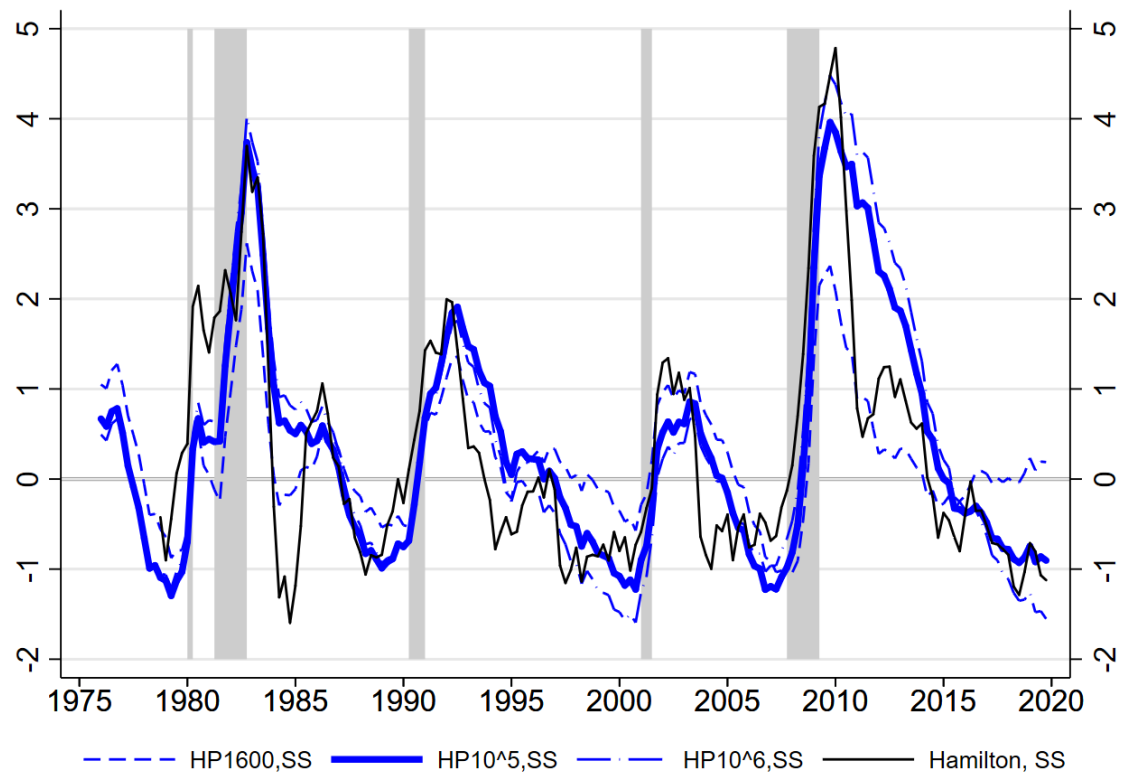

Note: Quarterly SA series, 1976Q1 - 2019Q4. Shaded areas denote NBER recessions. 